\title{
Qualidade da carne e desempenho de genótipos de suínos alimentados com dois níveis de aminoácidos
}

\author{
Teresinha Marisa Bertol ${ }^{(1)}$, Rogério Manoel Lemes de Campos $^{(2)}$, Arlei Coldebella ${ }^{(1)}$, Jonas Irineu dos Santos Filho(1),
} Elsio Antonio Pereira de Figueiredo ${ }^{(1)}$, Nelcindo Nascimento Terra ${ }^{(3)}$ e Ingrid Beatriz Lermen Agnes $^{(1)}$

(1)Embrapa Suínos e Aves, BR 153, Km 110, Vila Tamanduá, CEP 89700-000 Concórdia, SC. E-mail: tbertol@cnpsa.embrapa.br, arlei@cnpsa.embrapa.br, jonas@cnpsa.embrapa.br, elsio@cnpsa.embrapa.br, biaagnes_40@yahoo.com.br (2)Fundação Universidade Federal do Vale do São Francisco, Avenida José de Sá Maniçoba, s/nº, Centro, CEP 56304-205 Petrolina, PE. E-mail: rogeriocampos2007@yahoo.com.br

(3)Universidade Federal de Santa Maria, Faixa de Camobi, Km 09, Campus Universitário, CEP 97105-900 Santa Maria, RS. E-mail: nelcindo@terra.com.br.

Resumo - O objetivo deste trabalho foi avaliar a influência do genótipo e de teores de aminoácidos na dieta sobre o desempenho de suínos, o retorno econômico e a qualidade da carcaça e da carne. Os genótipos avaliados foram: MS115 x F1; Duroc x F1 (DCxF1); MS115 x Moura (MS115xMO); Duroc x 25\% Duroc, $50 \%$ Large White, 25\% Moura (DCxMO3). Os teores de aminoácidos nas dietas foram os recomendados para o desempenho alto ou médio de machos castrados com alto potencial genético. O escore de marmoreio foi mais elevado nos animais alimentados com teores médios de aminoácidos. Os genótipos DCxF1 e DCxMO3 tiveram maior ganho de peso diário do que MS115xF1 e MS115xMO. O menor ganho de peso, ajustado pelo consumo de ração, ocorreu no genótipo MS115xMO. As maiores espessuras de toucinho foram observadas nos animais MS115xMO e nos machos DCxMO3. O maior escore de marmoreio ocorreu nos animais MS115xMO, e o menor nos MS115xF1. Em comparação aos genótipos selecionados quanto à produção de carne, a raça Moura influenciou negativamente o desempenho e a qualidade da carcaça e positivamente a qualidade da carne, de acordo com sua proporção nos genótipos. A raça Duroc influenciou positivamente a qualidade da carne nos cruzamentos. A redução dos teores de aminoácidos nas dietas proporciona aumento do marmoreio, independentemente do genótipo.

Termos para indexação: Sus scrofa, marmoreio, nutrição, raças exóticas, raça Moura.

\section{Meat quality and performance of pig genotypes fed two amino acid levels}

\begin{abstract}
The objective of this work was to evaluate the effect of genotype and amino acid levels on swine performance, economic returns, and carcass and meat quality. The evaluated genotypes were: MS115 x F1; Duroc x F1 (DCxF1); MS115 x Moura (MS115xMO); Duroc x 25\% Duroc, 50\% Large White, 25\% Moura (DCxMO3). Diet amino acids contents were those recommended for high or medium performance of barrows with high genetic potential. Marbling score was higher in animals fed the lowest level of amino acids. The genotypes DCxF1 and DCxMO3 had higher daily weight gains than MS115xF1 and MS115xMO. The lowest weight gain, adjusted by feed intake, occurred in the genotype MS115xMO. The highest backfat thickness were observed in MS115xMO animals and DCxMO3 males. The highest marbling score occurred in MS115xMO animals and the lowest in MS115xF1 ones. In comparison to the genotypes selected for meat production, Moura breed affected the performance and carcass quality negatively, and affected the meat quality positively, depending on this breed proportion in the genotypes. Duroc breed affected meat quality positively in the genotypes. Diet-reduced amino acid contents increased marbling, regardless of the genotype.
\end{abstract}

Index terms: Sus scrofa, marbling, nutrition, exotic breeds, Moura breed.

\section{Introdução}

A produção de suínos evoluiu muito nas últimas décadas, em consequência de avanços no melhoramento genético, nutrição e sanidade. O alto padrão da carne suína, produzida atualmente, está relacionado a carcaças com baixa quantidade de gordura e à utilização de padrões sanitários e de segurança dos alimentos comparáveis ou superiores aos de outras carnes.
No entanto, toda essa evolução resultou, em alguns casos, em carne de qualidade inferior, em relação a aspectos tecnológicos e sensoriais.

Estudos que comparam linhagens de suínos, selecionadas para produzir carne magra, a linhagens controle, anteriores à seleção, apontam a redução da gordura intramuscular e escores inferiores de cor, marmoreio e firmeza nos animais selecionados (Cameron et al., 2000; Fabian et al., 2003). 
Algumas raças de suínos melhoradas, tais como a Duroc, são conhecidas pela melhor qualidade da carne em razão de maior quantidade de gordura intramuscular, mas com espessura de toucinho comparável ou até superior à de outras raças exóticas melhoradas (Edwards et al., 2003; Wood et al., 2004). A raça Moura, naturalizada no Brasil e com menor grau de seleção para produção de carne, tem elevada espessura de toucinho e pequena profundidade de lombo, o que resulta em baixa percentagem de carne magra na carcaça (Fávero et al., 2007) e, acredita-se, em elevado grau de marmoreio.

Por meio de cruzamentos das raças Duroc e Moura com genótipos provenientes do cruzamento de raças melhoradas, para se obter ganho de carne magra, espera-se obter uma melhoria da qualidade da carne, desempenho satisfatório e composição de carcaça compatível com produções comerciais modernas.

Com relação à melhoria da qualidade da carne, principalmente em termos de quantidade de gordura intramuscular, o objetivo é agregar valor ao produto, tanto para consumo in natura como de produtos processados, principalmente os curados e fermentados crus. Carnes com níveis de gordura intramuscular abaixo de $2 \%$ têm atributos sensoriais, tais como suculência e sabor, afetados negativamente (Fernandes et al., 1999a). Todavia, o aumento da gordura intramuscular até 3,5\% melhora a textura, o sabor e a aceitabilidade, desde que não associada a aumento da gordura visível (Fernandes et al., 1999b).

Alguns trabalhos mostram que gordura intramuscular mais elevada, obtida com dietas baixas em proteína, resulta em maior suculência e maciez da carne (Wood et al., 2004; Teye et al., 2006), conforme a raça e o músculo avaliado (Wood et al., 2004). Porém, as exigências de aminoácidos dos suínos variam com diversos fatores, entre eles raça ou genótipo, densidade energética da dieta, temperatura ambiente, densidade no alojamento e estado sanitário (National Research Council, 1998).

Entre os fatores genéticos, citam-se, principalmente, a taxa potencial de deposição de proteína corporal e a capacidadeparaconsumodiáriodealimento.Assim, raças ou cruzamentos com taxa de crescimento, capacidade de consumo e composição de carcaça diferenciadas terão diferentes exigências de aminoácidos. Além disso, dietas com baixos níveis de aminoácidos, em relação às exigências, tendem a proporcionar maior quantidade de gordura intramuscular em suínos (Teye et al., 2006; Alonso et al., 2010), embora este efeito possa ser dependente da raça (Wood et al., 2004).

O objetivo desse trabalho foi avaliar a influência do genótipo e de teores de aminoácidos na dieta sobre o desempenho, retorno econômico e qualidade da carcaça e da carne de suínos.

\section{Material e Métodos}

O experimento foi conduzido nas instalações da granja experimental da Embrapa Suínos e Aves, em Concórdia, SC. Foram utilizados 112 animais, com peso médio inicial de $23,36 \pm 2,49 \mathrm{~kg}$, recém-saídos da creche e que passaram por período de adaptação de 15 dias até o início do experimento.

Os genótipos resultaram dos cruzamentos de machos Duroc e Embrapa MS115 (62,5\% Pietrain, $18,75 \%$ Large White e $18,75 \%$ Duroc) com fêmeas Moura e F1 (Large White x Landrace) e foram avaliados nos seguintes grupos: 1, macho Embrapa MS115 x fêmea F1 (MS115xF1); 2, macho Duroc $x$ fêmea F1 (DCxF1); 3, macho Embrapa MS115 x fềmea Moura (MS115xMO); 4, macho Duroc x fêmea 25\% Duroc, 50\% Large White, 25\% Moura (DCxMO3).

Em cada grupo, foram comparados dois níveis de aminoácidos em fêmeas e em machos castrados. O delineamento foi o de blocos ao acaso (peso inicial dentro de sexo e genótipo), com os tratamentos dispostos em esquema fatorial $4 \times 2 \times 2$. Foram utilizados 23 animais (14 machos e 9 fêmeas) do genótipo resultante do cruzamento Moura x Embrapa MS115, e 28 animais (14 machos e 14 fêmeas) de cada um dos outros genótipos; cada animal representou uma repetição. Os dois níveis de aminoácidos utilizados foram os recomendados por Rostagno (2005), para o desempenho superior ou médio de machos castrados com alto potencial genético. Os níveis dos demais nutrientes foram similares entre as dietas dentro da mesma fase, e atenderam às recomendações dos mesmos autores (Tabela 1).

A ração foi fornecida à vontade, e as trocas de ração se deram de acordo com o peso vivo, aos 54,6, 73,7 e $99,7 \mathrm{~kg}$, em média. Os animais foram alojados em baias individuais, com divisórias ripadas, comedouro semiautomático e bebedouro automático, durante todo o período experimental. 
O abate foi feito em abatedouro comercial, em datas diferentes para cada grupo genético, de acordo com o período necessário para que o peso vivo médio atingisse aproximadamente $118 \mathrm{~kg}$. Os animais foram pesados no dia anterior ao abate. A ração foi retirada às $15 \mathrm{~h}$ e o carregamento foi feito às $3 \mathrm{~h}$ da manhã seguinte. O transporte durou 25 minutos, e o período de descanso pré-abate foi de três horas.

As variáveis de desempenho do crescimento foram avaliadas por meio de pesagens periódicas dos animais e do controle do consumo de ração. Após o abate, foram avaliadas a espessura de toucinho e a profundidade do lombo, de acordo com o procedimento de rotina do abatedouro, com uso de uma pistola de tipificação automática da marca SFK. Foram feitas duas avaliações do $\mathrm{pH}$, uma aos 45 minutos e outra 24 horas após o abate, no músculo longissimus dorsi, na altura da última costela (P2), com um medidor de $\mathrm{pH}$ portátil, da marca Hanna. Vinte e quatro horas após o abate, foi avaliada a cor pelo sistema CIE Lab (L*, a*, b*), com um colorímetro Minolta (Minolta Camera Ltda.,
Japão), em que: L indica a luminosidade; a indica a cromaticidade que tende do verde (-) ao vermelho $(+)$; e b indica a cromaticidade que varia do azul (-) até o amarelo $(+)$; também foram avaliados a cor e o marmoreio visual, por meio dos padrões da American Meat Science Association (2001). A saturação (S), que indica a intensidade da cor, foi calculada pela seguinte equação (Little, 1975): $\mathrm{S}=\left(\mathrm{a}^{* 2}+\mathrm{b}^{* 2}\right)^{0,5}$.

As cores visual e instrumental foram avaliadas após um período de exposição da amostra ao ar por 20 minutos, para estabilização do pigmento. Por ocasião dessa avaliação, também foram coletadas amostras do músculo longissimus dorsi e do semimembranosus, para avaliação da perda de água por gotejamento, além de amostras do longissimus dorsi para determinar gordura intramuscular.

A perda de água por gotejamento foi avaliada em amostras de 8 a 12 g, pesadas e colocadas em recipientes para suco de carne, com copo coletor do exsudato e, em seguida, refrigeradas com temperaturas entre 2 e $4{ }^{\circ} \mathrm{C}$, durante 48 horas. Ao final deste período, as amostras

Tabela 1. Ingredientes e composição nutricional das dietas experimentais com dois conteúdos de aminoácidos, em duas fases de crescimento e de terminação.

\begin{tabular}{|c|c|c|c|c|c|c|c|c|}
\hline \multirow[t]{2}{*}{ Composição } & \multicolumn{2}{|c|}{ Crescimento $1(35-55 \mathrm{~kg})$} & \multicolumn{2}{|c|}{ Crescimento $2(55-74 \mathrm{~kg})$} & \multicolumn{2}{|c|}{ Terminação $1(74-100 \mathrm{~kg})$} & \multicolumn{2}{|c|}{ Terminação $2(100-118 \mathrm{~kg})$} \\
\hline & Alto & Médio & Alto & Médio & Alto & Médio & Alto & Médio \\
\hline & \multicolumn{8}{|c|}{ Composição percentual dos ingredientes } \\
\hline Milho & 61,355 & 66,785 & 67,275 & 72,265 & 71,745 & 77,165 & 77,960 & 82,230 \\
\hline Farelo de soja & 33,520 & 28,330 & 29,990 & 24,990 & 26,040 & 20,600 & 19,940 & 15,600 \\
\hline Óleo & 2,090 & 1,860 & 0,000 & 0,000 & 0,000 & 0,000 & 0,000 & 0,000 \\
\hline Calcário & 0,710 & 0,720 & 0,580 & 0,590 & 0,420 & 0,420 & 0,370 & 0,380 \\
\hline Fosfato bicálcico & 1,290 & 1,340 & 1,100 & 1,140 & 0,960 & 1,010 & 1,020 & 1,060 \\
\hline Sal & 0,160 & 0,160 & 0,110 & 0,150 & 0,120 & 0,160 & 0,110 & 0,150 \\
\hline Cloreto de colina $60 \%$ & 0,140 & 0,140 & 0,140 & 0,140 & 0,050 & 0,050 & 0,000 & 0,000 \\
\hline L-lisina $\mathrm{HCl} 78 \%$ & 0,130 & 0,110 & 0,120 & 0,110 & 0,060 & 0,050 & 0,050 & 0,050 \\
\hline DL-metionina $99 \%$ & 0,260 & 0,240 & 0,070 & 0,030 & 0,030 & 0,000 & 0,000 & 0,000 \\
\hline L-treonina $98 \%$ & 0,140 & 0,110 & 0,110 & 0,080 & 0,070 & 0,040 & 0,040 & 0,020 \\
\hline Premix de vitaminas ${ }^{(1)}$ & 0,100 & 0,100 & 0,100 & 0,100 & 0,100 & 0,100 & 0,100 & 0,100 \\
\hline Premix de minerais ${ }^{(2)}$ & 0,100 & 0,100 & 0,100 & 0,100 & 0,100 & 0,100 & 0,100 & 0,100 \\
\hline Promotor de crescimento & 0,005 & 0,005 & 0,005 & 0,005 & 0,005 & 0,005 & 0,010 & 0,010 \\
\hline Adsorvente micotoxinas & 0,000 & 0,000 & 0,300 & 0,300 & 0,300 & 0,300 & 0,300 & 0,300 \\
\hline \multirow[t]{2}{*}{ Total } & 100,0 & 100,0 & 100,0 & 100,0 & 100,0 & 100,0 & 100,0 & 100,0 \\
\hline & \multicolumn{8}{|c|}{ Composição nutricional calculada } \\
\hline EM (kcal) & 3.340 & 3.340 & 3.255 & 3.266 & 3.282 & 3.294 & 3.301 & 3.310 \\
\hline Proteína bruta $(\%)$ & 19,02 & 17,08 & 18,44 & 16,60 & 17,03 & 15,03 & 14,79 & 13,19 \\
\hline Triptofano digestível (\%) & 0,18 & 0,16 & 0,17 & 0,15 & 0,15 & 0,13 & 0,13 & 0,11 \\
\hline Treonina digestível (\%) & 0,67 & 0,58 & 0,62 & 0,54 & 0,54 & 0,45 & 0,44 & 0,37 \\
\hline Lisina digestível (\%) & 1,03 & 0,89 & 0,95 & 0,83 & 0,81 & 0,68 & 0,66 & 0,56 \\
\hline Metionina digestível (\%) & 0,51 & 0,46 & 0,32 & 0,26 & 0,26 & 0,21 & 0,21 & 0,19 \\
\hline Met+cist digestível(\%) & 0,62 & 0,54 & 0,57 & 0,50 & 0,50 & 0,43 & 0,43 & 0,39 \\
\hline Cálcio $(\%)$ & 0,70 & 0,70 & 0,60 & 0,60 & 0,50 & 0,50 & 0,48 & 0,48 \\
\hline $\mathrm{P}$ disponível (\%) & 0,32 & 0,32 & 0,28 & 0,28 & 0,25 & 0,25 & 0,25 & 0,25 \\
\hline $\mathrm{Na}(\%)$ & 0,20 & 0,20 & 0,17 & 0,17 & 0,16 & 0,16 & 0,14 & 0,14 \\
\hline
\end{tabular}

${ }^{(1)}$ Conteúdo de vítaminas por quilo da dieta : 7.000 UI de vitamina A; 1.300 UI de vitamina D3; 40 UI de vitamina E; 1,5 mg de vitamina K3; 1,35 mg de vitamina B1; $4 \mathrm{mg}$ de vitamina B2; 2,3 mg de vitamina B6; 25 mcg de vitamina B12; 0,15 mg de biotina; 1 mg de ácido fólico; 30 mg de ácido nicotínico;

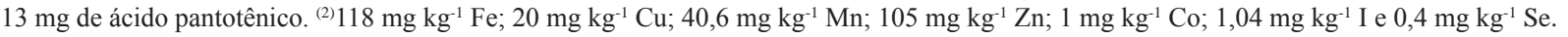


foram novamente pesadas, e a perda por gotejamento foi determinada em percentagem, pela diferença entre os pesos inicial e final da amostra (Honikel, 1998).

As amostras utilizadas para a avaliação da gordura intramuscular foram congeladas a $-20^{\circ} \mathrm{C}$, $\log$ o após a coleta. Posteriormente, elas foram descongeladas, moídas em multiprocessador, acondicionadas em embalagens de alumínio descartáveis e, novamente, congeladas, mantidas por 24 horas em freezer a $-25^{\circ} \mathrm{C}$ e liofilizadas a $-40^{\circ} \mathrm{C}$, até umidade constante utilizando o liofilizador Liobrás Modelo LP810 (Liobrás, São Carlos, Brasil).

Após a liofilização, as amostras foram moídas em moinho refrigerado Foss (Foss Analytical, Hoganas, Suécia) e armazenadas em freezer a $-25^{\circ} \mathrm{C}$, para análise da composição química proximal. A determinação da matéria seca foi feita de acordo com as normas analíticas do Pregnolatto \& Pregnolatto (1985), em estufa a $105^{\circ} \mathrm{C}$. A determinação da proteína bruta foi feita pelo método de Kjeldhal, a extração da gordura foi feita em aparelho Soxhlet (Foss Analytical, Hoganas, Suécia), com éter de petróleo, e as cinzas com a queima em mufla, ambas de acordo com os procedimentos descritos no Association of Official Analytical Chemists (1995).

Os dados foram submetidos à análise da variância por meio do procedimento GLM do SAS Institute (2001). Para estudo da eficiência alimentar, foi avaliado o ganho de peso diário, ajustado pela covariável consumo de ração. Os dados de espessura de toucinho e peso da carcaça quente foram ajustados com uso do peso ao abate como covariável.
Para comparação das médias, foi utilizado o teste de Tukey, a 5\% de probabilidade.

\section{Resultados e Discussão}

O conteúdo de aminoácidos nas dietas não influenciou nenhuma das variáveis de desempenho (Tabela 2). A maior parte das características avaliadas foi influenciada pelo genótipo.

Os leitões foram selecionados de forma a que a idade inicial fosse o mais próxima possível entre os genótipos e tratamentos. Apesar da maior diferença em idade entre os genótipos ser de apenas cinco dias, esta diferença foi significativa (Tabela 2). Da mesma forma, os pesos ao final do período de adaptação foram diferentes entre os genótipos, em razão das diferenças na taxa de crescimento das raças envolvidas. Os suínos DCxF1 apresentaram o maior peso ao final do período de adaptação, seguidos dos MS115xF1 e DCxMO3, e os leitões MS115xMO apresentaram o menor peso. Os animais foram abatidos em idades diferentes, para que atingissem peso final estatisticamente semelhante. O número de dias na fase crescimento-terminação e a idade de abate foram mais elevados nos animais do genótipo MS115xMO, seguidos dos MS115xF1, tendo sido os suínos DCxMO3 e os DCxF1 abatidos com menor idade (Tabela 2).

Da mesma forma que o peso de abate, o peso da carcaça quente não foi diferente $(p>0,05)$ entre os genótipos.Ainda assim, utilizou-se o peso ao abate como covariável, para ajustar os valores de peso da carcaça quente com intuito de reduzir o erro experimental.

Tabela 2. Média \pm erro-padrão das variáveis de desempenho e de carcaça dos genótipos avaliados ${ }^{(1)}$.

\begin{tabular}{|c|c|c|c|c|c|c|c|}
\hline \multirow[t]{2}{*}{ Variável dependente } & \multirow{2}{*}{$\begin{array}{l}\text { Conteúdo de } \\
\text { aminoácidos }\end{array}$} & \multirow[t]{2}{*}{ Sexo } & \multicolumn{4}{|c|}{ Genótipo } & \multirow[t]{2}{*}{$\mathrm{P}$} \\
\hline & & & $\mathrm{DCxF} 1$ & MS115xF1 & DCxMO3 & MS115xMO & \\
\hline Idade inicial (dias) & - & - & $65,6 \pm 0,18 \mathrm{a}$ & $63,7 \pm 0,09 b$ & $62,0 \pm 0,38 \mathrm{bc}$ & $60,3 \pm 0,98 \mathrm{c}$ & 0,001 \\
\hline Peso inicial $(\mathrm{kg})$ & - & - & $24,94 \pm 0,49 a$ & $23,82 \pm 0,43 b$ & $23,07 \pm 0,35 \mathrm{c}$ & $21,24 \pm 0,63 d$ & 0,001 \\
\hline Peso final fase adaptação $(\mathrm{kg})$ & - & - & $36,43 \pm 0,72 a$ & $32,23 \pm 0,64 b$ & $33,09 \pm 0,58 b$ & $29,35 \pm 0,92 \mathrm{c}$ & 0,001 \\
\hline Peso ao abate $(\mathrm{kg})$ & - & - & $119,91 \pm 2,20$ & $118,85 \pm 1,68$ & $118,70 \pm 1,58$ & $117,92 \pm 2,37$ & 0,57 \\
\hline Idade de abate (dias) & - & - & $165,6 \pm 0,2 \mathrm{c}$ & $173,7 \pm 0,1 \mathrm{~b}$ & $165,0 \pm 0,4 \mathrm{c}$ & $191,3 \pm 1,0 \mathrm{a}$ & 0,001 \\
\hline Dias em crescimento-terminação & - & - & $100,0 \pm 0,0 \mathrm{~d}$ & $110,0 \pm 0,0 \mathrm{~b}$ & $103,0 \pm 0,0 \mathrm{c}$ & $131,0 \pm 0,0 \mathrm{a}$ & 0,001 \\
\hline Ganho de peso diário $(\mathrm{kg})$ & - & - & $0,971 \pm 0,019 a$ & $0,902 \pm 0,014 b$ & $0,962 \pm 0,014 \mathrm{a}$ & $0,757 \pm 0,017 \mathrm{c}$ & 0,001 \\
\hline Conversão alimentar & - & - & $2,76 \pm 0,03 b$ & $2,67 \pm 0,03 b$ & $2,78 \pm 0,03 b$ & $3,12 \pm 0,04 \mathrm{a}$ & 0,001 \\
\hline Ganho de peso diário ajustado ${ }^{(2)}(\mathrm{kg})$ & - & - & $0,935 \pm 0,010 \mathrm{a}$ & $0,936 \pm 0,010 \mathrm{a}$ & $0,925 \pm 0,010 \mathrm{a}$ & $0,806 \pm 0,013 b$ & 0,001 \\
\hline \multirow[t]{2}{*}{ Consumo de ração diário $(\mathrm{kg})$} & Alto & - & $2,678 \pm 0,074 \mathrm{ab}$ & $2,330 \pm 0,067 \mathrm{~cd}$ & $2,773 \pm 0,071 \mathrm{a}$ & $2,291 \pm 0,075 \mathrm{~d}$ & \multirow[t]{2}{*}{0,05} \\
\hline & Médio & - & $2,675 \pm 0,083 \mathrm{ab}$ & $2,486 \pm 0,058 \mathrm{bcd}$ & $2,588 \pm 0,088 \mathrm{abc}$ & $2,426 \pm 0,096 \mathrm{bcd}$ & \\
\hline Peso da carcaça ajustado ${ }^{(3)}(\mathrm{kg})$ & - & - & $86,31 \pm 0,98$ & $85,16 \pm 1,03$ & $84,81 \pm 0,94$ & $86,39 \pm 1,14$ & 0,60 \\
\hline \multirow[t]{2}{*}{ Espessura de toucinho (mm) } & - & $\mathrm{F}$ & $17,78 \pm 1,41 \mathrm{abc}$ & $19,22 \pm 1,38 \mathrm{abc}$ & $19,10 \pm 1,58 \mathrm{abc}$ & $22,83 \pm 1,85 \mathrm{ab}$ & \multirow{2}{*}{0,05} \\
\hline & - & M & $14,69 \pm 1,48 \mathrm{c}$ & $15,67 \pm 1,63 \mathrm{bc}$ & $22,84 \pm 1,34 \mathrm{a}$ & $23,41 \pm 1,46 a$ & \\
\hline
\end{tabular}

${ }^{(1)}$ Médias seguidas de letras iguais, em uma mesma variável, não diferem pelo teste de Tukey, a $5 \%$ de probabilidade. ${ }^{(2)}$ Ajustado pelo consumo de ração como covariável. ${ }^{(3)}$ Ajustado pelo peso ao abate como covariável. 
Houve interação $(\mathrm{p}<0,05)$ entre genótipo e conteúdo de aminoácidos nas dietas, para a variável consumo diário de ração (Tabela 2). O maior consumo diário foi observado no genótipo DCxMO3, com o conteúdo mais elevado de aminoácidos, e no DCxF1, em ambos os conteúdos de aminoácidos (alto e médio); enquanto os suínos do genótipo MS115xMO, alimentados com elevado conteúdo de aminoácidos, e os MS115xF1, com ambos os conteúdos de aminoácidos, apresentaram os menores consumos. O baixo consumo de ração dos animais MS115xMO em dieta com elevado conteúdo de aminoácidos pode ser explicado pela menor exigência de aminoácidos destes animais, que satisfazem seus requerimentos com menor consumo da dieta. O baixo consumo dos animais MS115xF1 pode estar relacionado ao padrão das raças que compõem o MS115, que é um genótipo selecionado para melhoria da conversão alimentar e para produção de carne magra - características ligadas a baixo consumo voluntário de alimento - e que inclui na sua composição genética a raça Pietrain. A seleção de um genótipo para melhor conversão alimentar tende a induzir baixo consumo voluntário de alimento (Cameron et al., 1999). O alto consumo de alimento, dos animais que contêm Duroc em sua composição, era esperado, pois esta raça tem apresentado consumo superior ao de outras utilizadas em linhas macho (National Pork Producers Council, 1995). O mesmo tem sido observado em progênies de machos terminais que contêm Duroc (Auspurger et al., 2002).

$\mathrm{O}$ ganho de peso diário foi maior nos animais dos genótipos DCxF1 e DCxMO3, do que nos animais MS115xF1 e MS115xMO (Tabela 2). Este resultado pode ser atribuído, inicialmente, a diferenças genéticas quanto às taxas de crescimento (National Pork Producers Council, 1995), com reflexos na curva de crescimento e no peso à maturidade (Fisher et al., 2003), e pode ser atribuído também ao maior consumo de ração dos animais dos dois primeiros genótipos, comparadas aos de MS115xF1, já que a conversão alimentar foi semelhante entre os três. O menor ganho de peso diário, observado nos animais MS115xMO, também pode ser atribuído a diferenças genéticas da raça Moura quanto à taxa de crescimento (Fávero et al., 2007), ao consumo de ração e à conversão alimentar destes animais. $\mathrm{O}$ efeito do consumo de ração sobre o ganho de peso diário é demonstrado no ganho de peso ajustado por covariável, para o mesmo consumo de ração, que foi semelhante entre os genótipos DCxF1, MS115xF1 e MO3xMS115, e superior ao MS115xMO.

Os resultados deste estudo estão de acordo com os relatados por Fávero et al. (2007), que verificaram crescimento mais lento e pior conversão alimentar em suínos Moura puros, em comparação a animais resultantes do cruzamento MS60 xF1. Brandt et al. (2010) também observaram pior desempenho zootécnico em suínos de raças nativas não melhoradas e seus cruzamentos, em comparação a genótipos comerciais. Com relação ao efeito negativo da raça Pietrain sobre o consumo voluntário de alimento, à taxa de ganho diário de peso e ao efeito positivo da raça Duroc sobre estas mesmas variáveis, este trabalho também está de acordo com o National Pork Producers Council (1995), Augspurger et al. (2002) e Edwards et al. (2006).

Os animais com 50\% de raça Moura (MS115xMO) apresentaram desempenho zootécnico inferior àqueles com 12,5\% (DCxMO3) e aos demais genótipos avaliados. $\mathrm{O}$ alto consumo de alimento dos animais resultantes dos cruzamentos cujo cachaço terminal era o Duroc garantiu a estes animais ganho de peso superior em comparação aos resultantes do cruzamento com cachaços MS115; porém, a conversão alimentar e o ganho de peso ajustado pelo consumo foram semelhantes entre esses genótipos. Tais resultados estão de acordo com os relatos de Edwards et al. (2006), que observaram maior ganho de peso nas progênies de machos Duroc, em comparação aos de progênies de machos Pietrain, mas a eficiência alimentar foi semelhante entre os genótipos. Porém, esses resultados diferem dos de Latorre et al. (2003), que observaram ganho diário de peso mais elevado em suínos Duroc puros comparados a suínos Duroc x Large White e Pietrain $\mathrm{x}$ Large White, mas com consumo diário de alimento similar e conversão alimentar superior nos animais Duroc puros.

Foi observada interação $(\mathrm{p}<0,05)$ entre sexo e genótipo para a variável espessura de toucinho ajustada pelo peso ao abate (Tabela 2). As maiores espessuras de toucinho ocorreram nos machos e fêmeas MS115xMO e nos machos DCxMO3, enquanto as menores foram observadas nos machos DCxF1 e MS115xF1. Altas espessuras de toucinho eram esperadas nos suínos com maior percentagem da raça Moura, o que está de acordo com os dados de Fávero et al. (2007). Um fato inesperado foi a espessura de toucinho das fêmeas 
DCxF1 e MS115xF1, mais elevada do que nos machos dos mesmos genótipos.

Não houve interação entre os fatores genótipo, níveis de aminoácidos e sexo, em nenhuma das características de qualidade de carne avaliadas. Somente o marmoreio foi influenciado pelo nível nutricional, enquanto a maior parte dessas variáveis foi influenciada pelo genótipo (Tabela 3). Observou-se maior escore de marmoreio no lombo, nos animais que receberam a dieta com o menor conteúdo de aminoácidos (1,66 \pm $0,12$ vs. $1,92 \pm 0,11 ; \mathrm{p}<0,05)$. Estes resultados estão de acordo com os relatos de Wood et al. (2004), Teye et al. (2006) e Alonso et al. (2010), que observaram maior nível de gordura intramuscular em suínos alimentados com dietas com teor reduzido de proteína e baixa relação lisina/energia. No presente estudo, os níveis reduzidos de aminoácidos foram suficientes para elevar o marmoreio, sem, no entanto, prejudicar o desempenho nem aumentar a espessura de toucinho. Wood et al. (2004) e Teye et al. (2006), no entanto, relataram redução do ganho de peso diário com a redução do conteúdo de proteína.

Também foi observado o efeito de genótipo no escore visual de marmoreio (Tabela 3), que foi maior nos animais MS115xMO, e menor nos MS115xF1. Este resultado era esperado, pois a seleção para produção de carne magra reduz a gordura intramuscular (Cameron et al., 2000; Fabian et al., 2003), e a linha fêmea do cruzamento MS115xF1 é selecionada para carne magra, ao contrário da linha fêmea do cruzamento
MS115xMO. O segundo maior escore de marmoreio foi observado nos animais DCxF1, o que também foi relatado por outros autores em relação a Duroc e seus cruzamentos (Candek-Potocar et al., 2002; D'Souza \& Mullan, 2002; Suzuki et al., 2003; Wood et al., 2004; Olivares et al., 2009). O baixo escore de marmoreio do genótipo MS115xF1 também pode ser explicado pela presença da raça Pietrain, que normalmente imprime esta característica em sua progênie, ao contrário da raça Duroc (Edwards et al., 2003).

Os resultados de gordura intramuscular, determinada pela extração em laboratório, não coincidem exatamente com os dados de marmoreio. Esta variável sofreu alteração apenas dos efeitos principais de genótipo e sexo. Porém, os genótipos DCxF1, DCxMO3, e MS115xMO apresentaram valores de gordura intramuscular semelhantes entre si, enquanto o genótipo MS115xF1 apresentou o menor valor (Tabela 3), o que era esperado, pois os três primeiros continham ao menos uma linha de alto marmoreio, ao contrário do último.

Embora tenham sido observados resultados conflitantes entre os diferentes indicadores de gordura intramuscular, é possível afirmar que a presença da raça Moura nos genótipos proporcionou aumento na espessura de toucinho e na gordura intramuscular, enquanto a raça Duroc influenciou apenas a gordura intramuscular. Esta última variável é importante para a qualidade da carne, em razão de seu efeito sobre a suculência e a maciez da carne in natura (Teye et al.,

Tabela 3. Média \pm erro-padrão de variáveis de qualidade da carne do lombo e do pernil, nos genótipos de suínos avaliados ${ }^{(1)}$.

\begin{tabular}{|c|c|c|c|c|c|}
\hline \multirow[t]{2}{*}{ Variáveis dependentes } & \multicolumn{4}{|c|}{ Genótipo } & \multirow[t]{2}{*}{$\mathrm{P}$} \\
\hline & DCxF1 & MS115xF1 & DCxMO3 & MS115xMO & \\
\hline & \multicolumn{5}{|c|}{ Lombo } \\
\hline $\mathrm{L}^{*}$ & $45,65 \pm 0,57 \mathrm{ab}$ & $46,91 \pm 0,45 \mathrm{ab}$ & $47,21 \pm 0,39 a$ & $45,14 \pm 0,54 b$ & 0,02 \\
\hline$a^{*}$ & $6,89 \pm 0,26 \mathrm{ab}$ & $6,25 \pm 0,24 b$ & $7,48 \pm 0,21 \mathrm{a}$ & $6,85 \pm 0,31 \mathrm{ab}$ & 0,03 \\
\hline $\mathrm{b}^{*}$ & $1,61 \pm 0,31 \mathrm{ab}$ & $0,63 \pm 0,20 \mathrm{~b}$ & $1,79 \pm 0,19 \mathrm{a}$ & $0,76 \pm 0,24 \mathrm{ab}$ & 0,02 \\
\hline Escore visual de cor $^{(2)}$ & $2,08 \pm 0,08 b$ & $2,46 \pm 0,14 \mathrm{ab}$ & $2,56 \pm 0,12 \mathrm{ab}$ & $2,95 \pm 0,17 \mathrm{a}$ & 0,01 \\
\hline Saturação da cor & $7,24 \pm 0,27 \mathrm{ab}$ & $6,36 \pm 0,25 b$ & $7,73 \pm 0,23 \mathrm{a}$ & $6,96 \pm 0,33 \mathrm{ab}$ & 0,01 \\
\hline Escore visual de marmoreio ${ }^{(3)}$ & $1,98 \pm 0,13 \mathrm{ab}$ & $1,35 \pm 0,09 \mathrm{c}$ & $1,56 \pm 0,14 b c$ & $2,36 \pm 0,22 \mathrm{a}$ & 0,001 \\
\hline $\mathrm{pH} 45 \mathrm{~min}$ & $6,34 \pm 0,02 \mathrm{a}$ & $6,19 \pm 0,02 b$ & $6,46 \pm 0,05 a$ & $5,91 \pm 0,03 \mathrm{c}$ & 0,001 \\
\hline $\mathrm{pH} 24 \mathrm{~h}$ & $5,58 \pm 0,02$ & $5,62 \pm 0,02$ & $5,63 \pm 0,01$ & $5,64 \pm 0,01$ & 0,06 \\
\hline Perda de água por gotejamento $(\%)$ & $2,98 \pm 0,31 b$ & $3,40 \pm 0,27 b$ & $2,59 \pm 0,32 b$ & $4,55 \pm 0,42 \mathrm{a}$ & 0,001 \\
\hline Matéria seca $(\%)$ & $25,50 \pm 0,15 \mathrm{a}$ & $23,55 \pm 0,09 c$ & $25,29 \pm 0,11 \mathrm{a}$ & $24,23 \pm 0,20 b$ & 0,001 \\
\hline Gordura intramuscular $^{(4)}(\%)$ & $2,16 \pm 0,15 \mathrm{a}$ & $1,47 \pm 0,10 \mathrm{~b}$ & $2,56 \pm 0,16 a$ & $2,25 \pm 0,19 \mathrm{a}$ & 0,001 \\
\hline \multicolumn{6}{|c|}{ Pernil } \\
\hline Escore visual de cor & $2,37 \pm 0,11 \mathrm{c}$ & $3,08 \pm 0,11 b$ & $2,88 \pm 0,09 b$ & $3,64 \pm 0,14 \mathrm{a}$ & 0,001 \\
\hline $\mathrm{pH} 45 \mathrm{~min}$ & $6,43 \pm 0,03 \mathrm{a}$ & $6,21 \pm 0,03 b$ & $6,39 \pm 0,03 \mathrm{a}$ & $5,99 \pm 0,03 \mathrm{c}$ & 0,001 \\
\hline pH 24 horas & $5,61 \pm 0,02 \mathrm{a}$ & $5,68 \pm 0,02 a$ & $5,66 \pm 0,01 \mathrm{a}$ & $5,65 \pm 0,02 \mathrm{a}$ & 0,05 \\
\hline
\end{tabular}

${ }^{(1)}$ Médias seguidas de letras iguais, nas linhas, não diferem pelo teste de Tukey, a 5\% de probabilidade. ${ }^{(2)}$ Escore visual de 1 a 6 , em que 1 indica rosa pálido e 6 vermelho escuro (American Meat Science Association, 2001). ${ }^{(3)}$ Escore visual de 1 a 10, em que 1 indica $1 \%$ de gordura intramuscular e 10 indica $10 \%$ (American Meat Science Association, 2001). ${ }^{(4)}$ Determinada por extração em laboratório (extrato etéreo). 
2006; Alonso et al., 2010) e sobre o sabor e textura dos produtos processados curados.

Os animais DCxMO3 apresentaram os maiores valores de $L^{*}$, $a^{*}$ e $b^{*}$ (Tabela 3 ). Os menores valores de $\mathrm{L}^{*}$ foram observados nos animais MS115xMO. A maior intensidade da cor, indicada pela saturação da cor, ocorreu nos animais DCxMO3 e a menor nos animais MS115xF1. Os maiores valores de $a^{*}$ e a maior saturação da cor na carne dos animais DCxMO3 indicam carne com tendência para uma coloração mais avermelhada, mas com alta luminosidade dada pelo maior valor de $\mathrm{L}^{*}$. Para os escores visuais de cor do lombo e do pernil, os maiores valores foram observados nos animais MS115xMO, e os menores nos animais DCxF1. Com a análise conjunta dos valores de $\mathrm{L}^{*}, \mathrm{a}^{*} \mathrm{e}$ $b^{*}$, saturação da cor e escores visuais de cor, verificouse que os animais MS115xMO e DCxMO3 tiveram as características mais favoráveis, dadas pela coloração mais escura (maior escore visual) e com menor luminosidade (menor valor de $\mathrm{L}^{*}$ ) em MS115xMO, e pela coloração mais avermelhada (maior valor de a*) e mais intensa (maior saturação da cor) em DCxMO3.

$\mathrm{O}$ pH medido 45 minutos após o abate também variou entre os genótipos avaliados (Tabela 3). Os menores valores, tanto do lombo quanto do pernil, foram observados nos animais MS115xMO, e os mais elevados nos animais DCxF1 e DCxMO3. Com relação ao pH medido 24 horas após o abate, não foram observadas diferenças significativas entre os genótipos, na análise de variância do lombo e no teste de médias para o pernil. Esperava-se que os genótipos com raça Moura tivessem $\mathrm{pH}$ mais elevado do que os demais, o que efetivamente ocorreu no genótipo DCxMO3, mas não no MS115xMO, já que a seleção para carne magra e desempenho zootécnico em outras raças tem levado a uma deterioração dos aspectos tecnológicos e sensoriais da carne (Cameron et al., 2000; Fabian et al., 2003; Gilbert et al., 2007). É provável que as raças envolvidas no lado paterno desses cruzamentos tenham desempenhado um papel fundamental para as diferenças observadas nesta variável, entre os genótipos avaliados.

A perda de água por gotejamento no lombo foi mais elevada nos animais MS115xMO do que nos demais genótipos (Tabela 3). No pernil, a perda de água por gotejamento mais elevada foi observada nos animais MS115xF1, e a menor foi no DCxMO3. A maior perda de água do lombo por gotejamento, observada nos animais MS115xMO, coincide com os baixos valores de $\mathrm{pH}$ medidos 45 minutos após o abate, o que poderia ser indício de ocorrência de carne PSE ("pale, soft and exudative", ou pálida, macia e exsudativa) neste genótipo; porém, os baixos valores de $\mathrm{L}^{*}$ e o alto escore visual da cor não confirmaram isto.

Os resultados obtidos no presente estudo, quanto aos aspectos da qualidade de carne que dependem mais diretamente do manejo pré-abate, tais como pH aos 45 minutos após o abate, cor e perda de água por gotejamento, devem ser analisados com reserva, pois os animais foram abatidos em datas diferentes, 0 que inevitavelmente acarreta variações nas variáveis ambientais e de manejo. É de conhecimento geral a interferência destes fatores na qualidade da carne. Portanto, estas características necessitam ser mais bem avaliadas em estudos com abate simultâneo dos diferentes genótipos.

Em termos econômicos, como a conversão alimentar não diferiu entre os genótipos MS115xF1, DCxF1 e DCxMO3, pode-se dizer que o custo de produção no crescimento-terminação foi semelhante entre os três genótipos. No entanto, em razão da pior conversão alimentar e maior tempo para atingir o peso de abate, os animais MS115xMO tiveram maior custo de produção. Em relação à receita, somente com os dados de espessura de toucinho, é possível ordenar os tratamentos quanto à remuneração das carcaças. A espessura de toucinho é o principal componente nas equações utilizadas na agroindústria para a definição da percentagem de carne magra nas carcaças (Guidoni, 2000). Assim, para um mesmo peso de abate, no mercado convencional, onde o pagamento é feito em função da percentagem de carne magra (Guidoni, 2000), é possível afirmar que a receita mais elevada será obtida nos genótipos MS115xF1 e DCxF1, seguida pela dos DCxMO3 e, por último, a dos genótipos MS115xMO, em razão da maior espessura de toucinho e, consequentemente, menor percentagem de carne magra nestes dois últimos.

\section{Conclusões}

1. A inclusão da raça Moura em alta proporção nos cruzamentos influencia negativamente o desempenho zootécnico, e deve ser recomendada somente para atender mercados alternativos que paguem prêmio pela melhor qualidade da carne, tanto in natura como em produtos processados. 
2. Os genótipos que contêm Duroc apresentam melhor desempenho zootécnico que os demais genótipos avaliados.

3. A raça Moura influencia negativamente a qualidade da carcaça e positivamente a qualidade da carne, a depender de sua proporção nos cruzamentos.

4. A raça Duroc influencia positivamente a qualidade da carne nos cruzamentos.

5. Conteúdos reduzidos de aminoácidos proporcionam aumento do marmoreio, independentemente do genótipo utilizado, mas não prejudicam o desempenho zootécnico.

\section{Referências}

ALONSO, V.; MAR CAMPO, M. del; PROVINCIAL, L.; RONCALÉS, P.; BELTRÁN, J.A. Effect of protein level in commercial diets on pork meat quality. Meat Science, v.85, p.7-14, 2010 .

AMERICAN MEAT SCIENCE ASSOCIATION. Meat evaluation handbook. Savoy: American Meat Science Association, 2001. $161 \mathrm{p}$.

ASSOCIATION OF OFFICIAL ANALYTICAL CHEMISTS. Fat (crude) of ether extract in animal feed. In: ASSOCIATION OF OFFICIAL ANALYTICAL CHEMISTS. Official methods of analysis of AOAC International. $16^{\text {th }}$ ed. Arlington: AOAC, 1995. v.1, p.17. Edited by Patrícia Cunniff.

AUGSPURGER, N.R.; ELLIS, M.; HAMILTON, D.N.; WOLTER, B.F.; BEVERLY, J.L.; WILSON, E.R. The effect of sire line on the feeding patterns of grow-finish pigs. Applied Animal Behaviour Science, v.75, p.103-114, 2002.

BRANDT, H.; WERNER, D.N.; BAULAIN, U.; BRADE, W.; WEISSMANN, F. Genotype-environment interactions for growth and carcass traits in different pig breeds kept under conventional and organic production systems. Animal, v.4, p.535-544, 2010.

CAMERON, N.D.; ENSER, M.; NUTE, G.R.; WHITTINGTON, F.M.; PENMAN, J.C.; FISKEN, A.C.; PERRY, A.M.; WOOD, J.D. Genotype with nutrition interaction on fatty acid composition of intramuscular fat and the relationship with flavour of pig meat. Meat Science, v.55, p.187-195, 2000.

CAMERON, N.D.; PENMAN, J.C.; FISKEN, A.C.; NUTE, G.R.; PERRY, A.M.; WOOD, J.D. Genotype with nutrition interactions for carcass composition and meat quality in pig genotypes selected for components of efficient lean growth rate. Animal Science, v.69, p.69-80, 1999.

CANDEK-POTOKAR, M.; MONIN, G.; ZLENDER, B. Pork quality, processing, and sensory characteristics of dry-cured hams as influenced by Duroc crossing and sex. Journal of Animal Science, v.80, p.988-996, 2002.

D'SOUZA, D.N.; MULLAN, B.P. The effect of genotype, sex and management strategy on the eating quality of pork. Meat Science, v.60, p.95-101, 2002.
EDWARDS, D.B.; BATES, R.O.; OSBURN, W.N. Evaluation of Duroc- vs. Pietrain-sired pigs for carcass and meat quality measures. Journal of Animal Science, v.81, p.1895-1899, 2003.

EDWARDS, D.B.; TEMPELMAN, R.J.; BATES, R.O. Evaluation of Duroc- vs. Pietrain-sired pigs for growth and composition. Journal of Animal Science, v.84, p.266-275, 2006.

FABIAN, J.; CHIBA, L.I.; KUHLERS, D.L.; FROBISH, L.T.; NADARAJAH, K.; MCELHENNEY, W.H. Growth performance, dry matter and nitrogen digestibilities, serum profile, and carcass and meat quality of pigs with distinct genotypes. Journal of Animal Science, v.81, p.1142-1149, 2003.

FÁVERO, J.A.; FIGUEIREDO, E.P. de; FEDALTO, L.M.; WOLOSZYN, N. A raça de suínos Moura como alternativa para a produção agroecológica de carne. Revista Brasileira de Agroecologia, v.2, p.1662-1665, 2007.

FERNANDES, X.; MONIN, G.; TALMANT, A.; MOUROT, J.; LEBRET, B. Influence of intramuscular fat content on the quality of pig meat -1 . Composition of the lipid fraction and sensory characteristics of m. longissimus lumborum. Meat Science, v.53, p.59-65, 1999a.

FERNANDES, X.; MONIN, G.; TALMANT, A.; MOUROT, J.; LEBRET, B. Influence of intramuscular fat content on the quality of pig meat -2 . Consumer acceptability of $\mathrm{m}$. longissimus lumborum. Meat Science, v.53, p.67-72, 1999b.

FISHER, A.V.; GREEN, D.M.; WHITTEMORE, C.T.; WOOD, J.D.; SCHOFIELD, C.P. Growth of carcass components and its relation with conformation in pigs of three genotypes. Meat Science, v.65, p.639-650, 2003.

GILBERT, H.; BIDANEL, J.P.; GRUAND, J.; CARITEZ, J.C.; BILLON, Y.; GUILlOUET, P.; LAGANT, H.; NOBLET, J.; SELLIER, P. Genetic parameters for residual feed intake in growing pigs, with emphasis on genetic relationships with carcass and meat quality traits. Journal of Animal Science, v.85, p.3182-3188, 2007.

GUIDONI, A.L. Melhoria de processos para a tipificação e valorização de carcaças suínas no Brasil. In: CONFERÊNCIA INTERNACIONAL VIRTUAL SOBRE QUALIDADE DE CARNE SUÍNA, 1., 2000, Concórdia. Anais. Concórdia: Embrapa Suínos e Aves, 2000. p.221-234. Disponível em: <http://www. cnpsa.embrapa.br/sgc/sgc_publicacoes/anais00cv_guidoni_ pt.pdf>. Acesso em: 04 mar. 2010.

HONIKEL, K.O. Reference methods for the assessment of physical characteristics of meat. Meat Science, v.49, p.447-457, 1998.

LATORRE, M.A.; MEDEL, P.; FUENTETAJA, A.; LÁZARO, R.; MATEOS, G.G. Effect of gender, terminal sire line and age at slaughter on performance, carcass characteristics and meat quality of heavy pigs. Animal Science, v.77, p.33-45, 2003.

LITTLE, A.C. Off on a tangent. Journal of Food Science, v.40, p.410-411, 1975.

NATIONAL PORK PRODUCERS COUNCIL. Special report: national genetic evaluation program. Overland Park: Intertec, 1995. 30p.

NATIONAL RESEARCH COUNCIL. Nutrient requirements of swine. $10^{\text {th }}$ rev. ed. Washington: National Academy, 1998. 211p. 
PREGNOLATTO, W.; PREGNOLATTO, N.P. (Coord.). Normas analíticas do Instituto Adolfo Lutz: métodos químicos e físicos para análise de alimentos. 3.ed. São Paulo: Instituto Adolfo Lutz, 1985. v.1, 42p.

OLIVARES, A.; DAZA, A; REY, A.I.; LOPEZ-BOTE, C.J. Interactions between genotype, dietary fat saturation and vitamin A concentration on intramuscular fat content and fatty acid composition in pigs. Meat Science, v.82, p.6-12, 2009.

ROSTAGNO, H.S. (Ed.). Tabelas brasileiras para aves e suínos: composição de alimentos e exigências nutricionais. 2.ed. Viçosa: UFV, 2005. 186p.

SAS INSTITUTE. SAS/STAT user's guide: statistics. Version 8. Cary: SAS Institute, 2001. 155p.
SUZUKI, K.; SHIBATA, T.; KADOWAKI, H.; ABE, H.; TOYOSHIMA, T. Meat quality comparison of Berkshire, Duroc and crossbred pigs sired by Berkshire and Duroc. Meat Science, v.64, p.35-42, 2003.

TEYE, G.A.; SHEARD, P.R.; WHITTINGTON, F.M.; NUTE, G.R.; STEWART, A.; WOOD, J.D. Influence of dietary oils and protein level on pork quality. 1. Effects on muscle fatty acid composition, carcass, meat and eating quality. Meat Science, v.73, p.157-165. 2006.

WOOD, J.D.; NUTE, G.R.;RICHARDSON, R.I.;WHITTINGTON, F.M.; SOUTHWOOD, O.; PLASTOW, G.; MANSBRIDGE, R.; COSTA, N. da; CHANG, K.C. Effects of breed, diet and muscle on fat deposition and eating quality in pigs. Meat Science, v.67, p.651-667, 2004.

Recebido em 22 de março de 2010 e aprovado em 27 de maio de 2010 